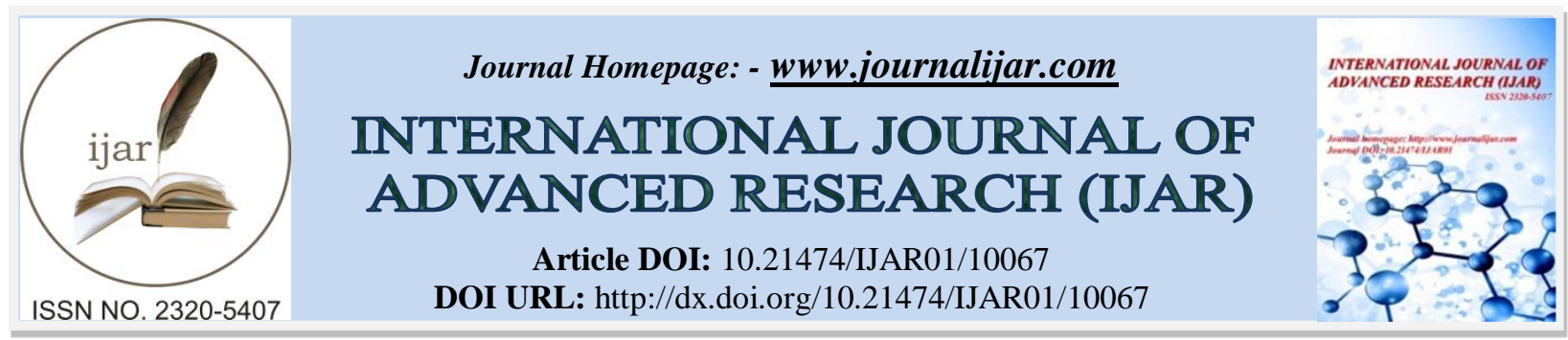

RESEARCH ARTICLE

\title{
ON THE PROCESS OF SEPARATING A SAW FIBER, PERFECTING CONSTRUCTION OF MACHINE TO GET ADDITIONAL COTTON SEED.
}

Safarov N.Q, Yangiboyev R.M, Erdanov A.M, Raxmonqulov J.E and Diyarov X.G.

Termez branch of Tashkent State Technical University named after Islam Karimov.

\section{Manuscript Info}

\section{Manuscript History}

Received: 12 September 2019

Final Accepted: 14 October 2019

Published: November 2019

\section{Key words:-}

saw ginie, front fart, working kamera, seeding machine, saw, whell grille, fiber, seeds.

\begin{abstract}
The article determines the possibility of ejaculation of bare seeds from the working chamber of the genie using auxiliary ejaculatory devices. Based on theoretical and experimental studies, results were obtained to improve the quality of fiber, seeds and gin productivity in the allocation of bare seeds from the working chamber. An analysis of the existing designs of saw gins showed that modern equipment is not efficient enough in light of the increasing demands on performance and fiber quality. The issue of highlighting bare seeds from the working chamber during ginning of raw cotton, as well as the influence of the density of the raw roller on the main technological indicators of gin, has not been sufficiently studied. The study of this issue allowed us to develop and choose the optimal design of the vas deferens in the working chamber of the gin, which contribute to increased productivity and fiber quality.
\end{abstract}

Copy Right, IJAR, 2019,. All rights reserved.

\section{Introduction:-}

It is known that of cotton seeds during on the process separation saw of ginning from fiber is a very complex process, because its its operation depends on the time of the seeds being in the working chamber and its output.. This process depends on structure of working chamber, the condition comb of cotton seed and yield of work.

Cotton falling from the supply the part of machine of saw gin to the working chamber separates $98 \%$ of the cotton fiber within 50 seconds, $t$ give us to reach 28-30 per cent through the seed comb, more 50 percent residues will remain in the working chamber, As a result, the saws are several times hit in the teeth and the quality of seed will impaired.

Without cotton seed staying is a long time in working chamber will affect the yield of work machine performance, fiber and of the cotton seed quality.

The efficiency of the working chamber can be improved by increasing the mass of cotton seeds in the camera or by reduce being time in the camera.

To get increasing the cotton mass, it is necessary to increase the transverse section of the chamber which is (when the saw diameter does not change) to get by preventing rotation with seeds of cotton by increasing the friction force on the chamber walls.

Corresponding Author:- Safarov N.Q.

Address: Termez branch of Tashkent State Technical University named after Islam Karimov. 
Therefore, the productively of working chamber can be only increased by reducing the average being time of the cotton seeds to the chamber.

Theoretical and practical investigations have shown that with saw fiber in the working chamber to take high the quality of cotton seeds, the fiber and high the productively machine of producing soon hairless seeds from working chamber by using auxiliary seed extractor hairless seeds in the chamber separator working chamber.

\section{Epxperimental And Discussion:-}

\section{Design of the ejaculatory device}

Experimental studies to find the optimal design and parameters of the vas defferencing device for rotation of the raw roller were carried out by introducing into the working chamber of the CRD a cylindrical tube of the vas deferencing device. For this, three designs of the ejaculatory device were made.

The first design of the vas deferens is a cylindrical pipe shape with an external diameter of $100 \mathrm{~mm}$, an internal pipe diameter of $90 \mathrm{~mm}$, inside of which a relatively fixed screw with right and left screw windings is fixed. The screw diameter is $90 \mathrm{~mm}$. The pipe holes are oval with a cross-sectional area of $0.70 \mathrm{sm}^{2}$. The device was made of steel grade Steel-3, with a cylindrical pipe thickness of 5.0-0.1 mm, a screw pen thickness of 2.00-0.1 mm, and a screw pitch of $100 \mathrm{~mm}$. (pic 1).

\section{Pic 1:-}
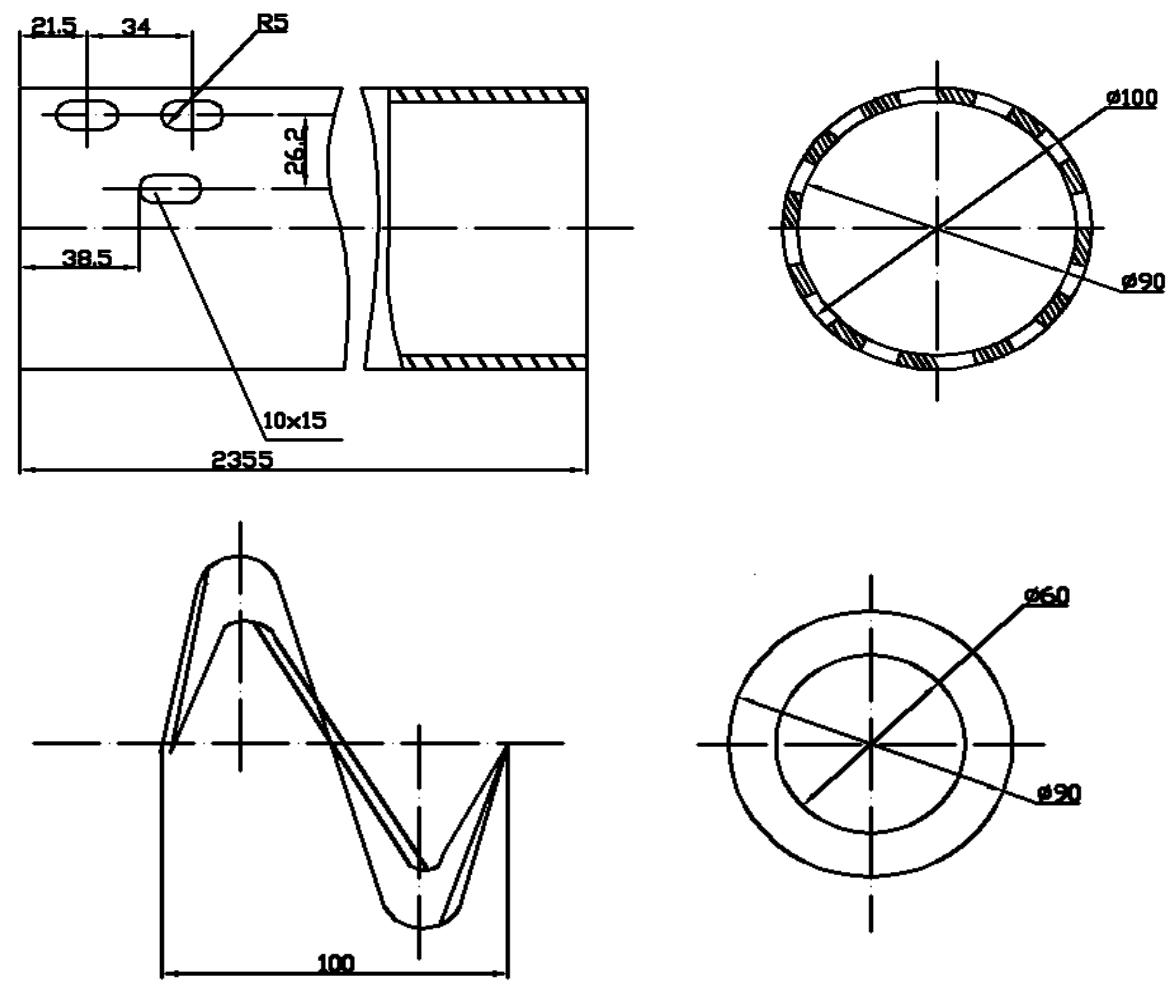

The seed-removing device of the first design, rotating the raw mass at a speed of 100-130 min with a gin productivity of not more than $7-8 \mathrm{~kg}$ of fiber per saw per hour. Seeds were withdrawn with great fragmentation, and the stationary screw of the vas deferens was severely damaged. As a result of this, it was not possible to increase the productivity of gin by more than $8.0 \mathrm{~kg}$ of fiber per hour.

The second design of the vas deferens is a cylindrical pipe shape with an external diameter of $140 \mathrm{~mm}$, an internal pipe diameter of $130 \mathrm{~mm}$, inside of which a relatively motionless screw with right and left screw windings is fixed. . The screw diameter is $130 \mathrm{~mm}$. The pipe holes are oval with a cross-sectional area of $1.20 \mathrm{sm}^{2}$. The device was made of steel of Steel-3 grade, the thickness of the cylindrical shape of the pipe was 5.0-0.1 mm, the thickness of the 
feather of the screw $2.00-0.1 \mathrm{~mm}$, the pitch of the screw $150 \mathrm{~mm}$. In the working position of the vas deferens entered $52-54 \mathrm{~mm}$ into the interspinous space of the saw cylinder. (pic 2).

Pic 2:-
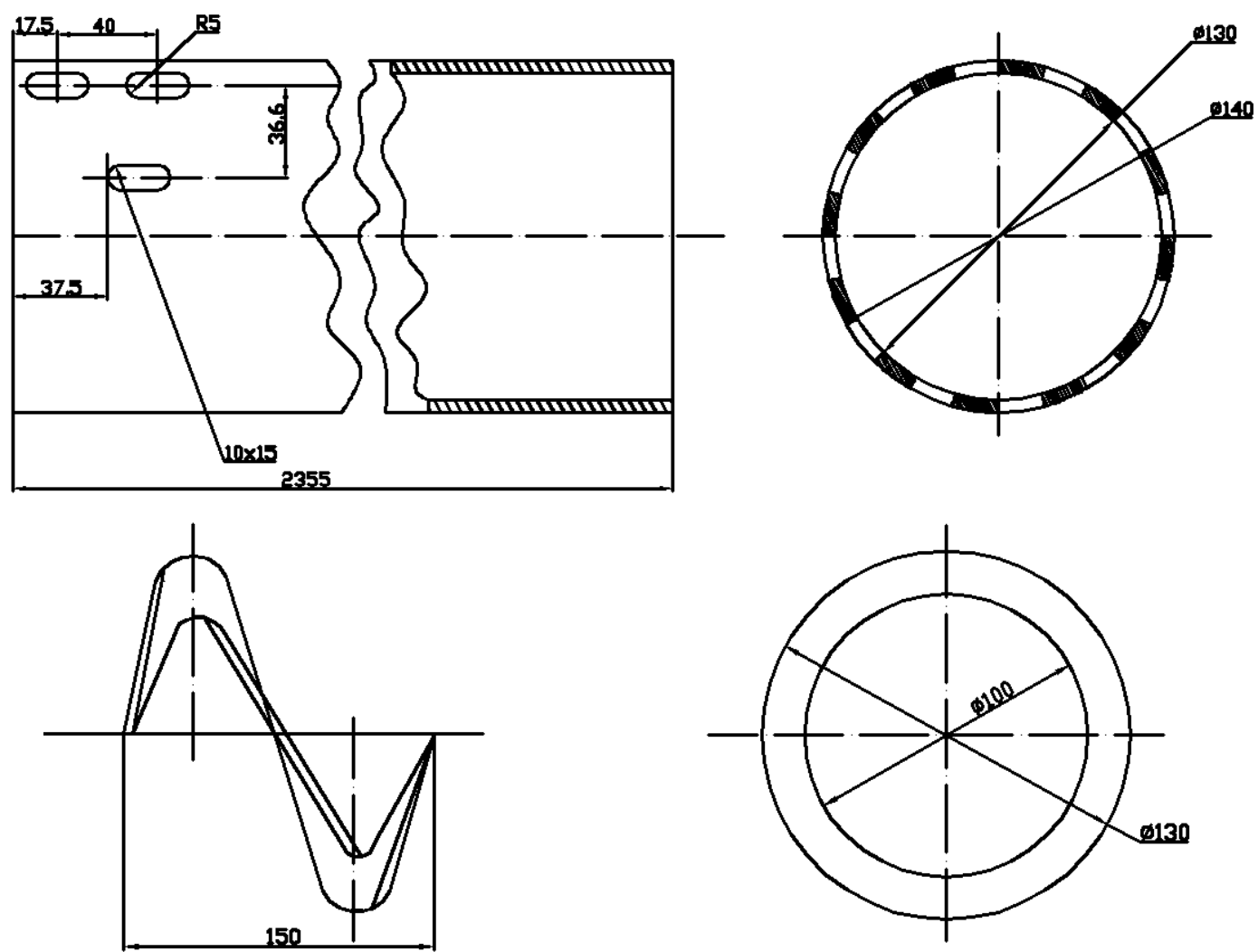

During the work of the vas deferencing device of this design, damage to it with a fixed screw continued, due to which the seeds came out of the chamber severely damaged, but the slaughter of the raw roller was not observed. However, the performance of the genie increased by only $3 \mathrm{~kg}$ compared to the first design.

The third design of the ejaculatory device is a cylindrical pipe shape with an external diameter of $165 \mathrm{~mm}$, an internal diameter of the pipe of $154 \mathrm{~mm}$, inside of which a relatively stale screw with right and left screw winding is fixed. . The screw diameter is $154 \mathrm{~mm}$. The pipe hole is oval with a cross-sectional area of $1.77 \mathrm{~cm} 2$. The device was made of steel grade Steel-3, the thickness of the cylindrical shape of the pipe was 5.0-0.1 mm, the thickness of the feather of the screw $2.00-0.1 \mathrm{~mm}$, the pitch of the screw $125 \mathrm{~mm}$. In the working position of the ejaculatory device, 38-40 mm entered between the saw space of the saw cylinder (pic 3).

\section{Pic 3:-}



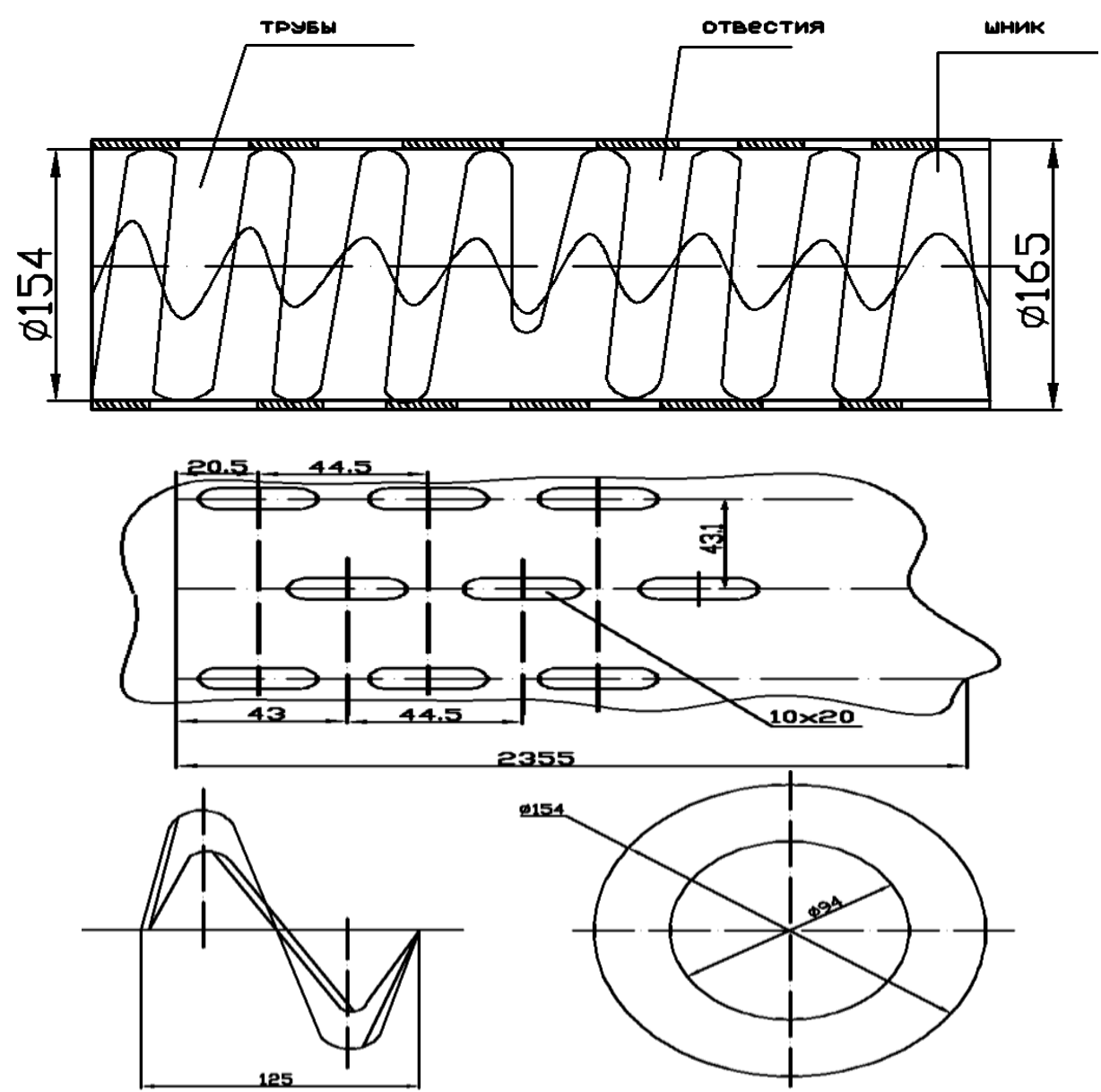

The third-type vas deferencing device worked more reliably than other designs, the gin productivity increased by 4-5 kg compared to the first design, the seed yield improved, seed crushing was not observed, but some bending of the fixed auger of the vas deferens continued.

The conducted experimental studies on the choice of the design of the ejaculatory device shows that the most optimal design of the ejaculatory device is an external diameter of $165 \mathrm{~mm}$, an internal diameter of $154 \mathrm{~mm}$. The holes of the pipe are oval in shape with a cross-sectional area of $1.77 \mathrm{sm}^{2}$ screw pitch $125 \mathrm{~mm}$, the thickness of the screw feather $2.00-0.1 \mathrm{~mm}$.

At the same time, gin productivity was not achieved above $12-13.5 \mathrm{~kg}$ of fiber per saw per hour. Attempts to increase the nutrition of gin with raw cotton led to a re-compaction of the raw mass, because it increased the number of exposed seeds, which led to the slaughter of the working chamber. This phenomenon also occurred when the sperm output device of various speed numbers.

The above studies on the choice of the design of the ejaculatory device showed that it is impossible to achieve a significant increase in productivity on the genie with the ejaculatory device of the optimal design (pic. 4) when the latter is installed in the working chamber of the type CRD.

As a result of this, further studies were aimed at finding the optimal profile of the working chamber, which would ensure a further increase in the performance of the genie when installing a vas deferencing device of the chosen design.

Pic 4:- 


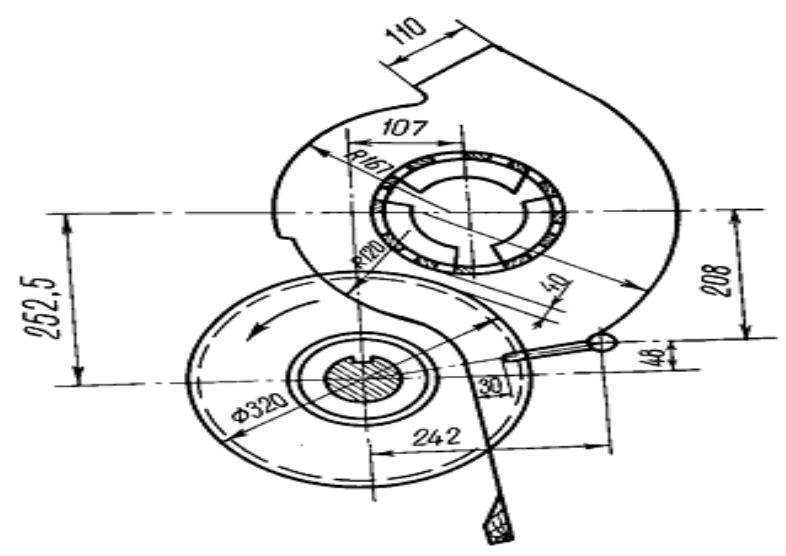

\section{Profile of the working chamber}

It is known that the working chamber of the saw gin is formed by the grate, frontal wall, throat of the chamber and an apron with a seed comb. All these elements of the chamber, the shape and size of their wiring in relation to the saw cylinder significantly affect the progress of the ginning process. Let us briefly consider the purpose of individual elements of the working chamber of the genie and the effect of their size on the process. The frontal wall of the chamber is a guiding surface for the formation of a raw roller on the shape of which the size of its diameter depends. The shape of the apron in the upper part, departing from the forming raw roller, creates a wedge-shaped pharynx to capture the raw cotton coming from the feeder tray, it significantly affects the performance of the gin. The direction of the surface of the apron and the lower part of the chamber near the seed comb forms an expansion in this zone and thereby creates favorable conditions for the separation of bare seeds from the mass of the raw roller. The presence of a seed comb, mounted flush in the lower part of it, contributes to the release of engineered seeds from the chamber, adjusting the degree of exposure of them.

The grate of the working chamber of the gin serves to enter saw blades of the saw cylinder into it through the grate and make the main process of ginning the separation of fiber from seeds. Through the throat of the chamber, cotton is fed. The raw roller, the size of which also affects the performance of the gin, is associated with the profiles and dimensions of the frontal beam and apron.

Reducing the radius of curvature of the frontal wall, you can increase the pressure, and decreasing the size between the vertical axis of the working chamber and the saw cylinder, you can reduce the pressure on the entire arc of cutting, along which the selection of seeds.

By changing the size of the apron profile and the coordinates of the seed comb installation, you can influence the degree and period of fiber capture by the saw tooth, exposure and seed extraction from the gin chamber.

Considering the foregoing, various options for the working chamber were made to select the optimal profile of the gin working chamber with the vas deferens rotation of the raw roller.

When constructing the working chamber, the size of the angle between the saw tooth and the surface of the grate in the zone of separation of the fiber from the seeds, the depth of cutting of the saws remained constant. And their speed, size from the surface of the grate to the ends of the seed comb in the zone of seed selection, the selected design of the vas deferencing device and its coordinates of the center of rotation with respect to the saw cylinder remained constant.

Observations and repeated checks of the gin's working capacity with the seed shaft rotation device of the raw roller in the new optimal profile of the working chamber show that normal rotation of the raw roller is carried out in it, new portions of raw cotton are received by the throat chamber, exposure and isolation of normally exposed seeds, ginning process, remove the fibers from saw teeth and gin waste. At the same time, the maximum productivity with an ejaculatory device of optimal design (with an external diameter of the ejaculation device is $165 \mathrm{~mm}$, the inner pipe is $154 \mathrm{~mm}$, inside of which a relatively stale screw with right and left screw windings is fixed. The screw diameter is $154 \mathrm{~mm}$. The pipe holes are oval with a cross-sectional area $1.77 \mathrm{sm}^{2}$.) A productivity of $13.8-14.2 \mathrm{~kg}$ of fiber per saw per hour was achieved. 
Further research is aimed at studying the process of ginning in gin with a vas deferencing device for rotating a raw roller introduced into a new optimal profile of the working chamber, and choosing the optimal speed of rotation of a vas deferencing device.

The results of the experiments were processed by mathematical methods of planning the experiment, which allow finding the solution to the problem close to optimal with minimal costs.

\section{Conclusion:-}

Installation of auxiliary cotton seed separating equipment to the central part of the saw gin working chamber, to getting high productively of machine $14.2 \mathrm{~kg}$ saw $/ \mathrm{h}$ speed up separate the cotton seeds on the process by output hairless seeds which accumulated on central, the mechanic injury of cotton seeds reduced up to 6 percentage obtained, composition of fiber the amount of dirtnees degree was reduced up to 0.2-0.3 percentage.

By reducing the raw material density of the working chamber, it has been able to reduce the load on the shaft and reduce the power consumption of the motor and increase the life of the saws between the saws.

In the central part of the working chamber, three different types of extration of cotton seed devices have been developed and tested, the experimental results have been selected mainly by the optimal version then have been the total surface area of the ellips holes is $1168 \mathrm{~cm} 2$, it consisted of two different types of diameter outside diameter $165 \mathrm{~mm}$ and internal diameter $154 \mathrm{~mm}$.

\section{List of References:-}

1. "Safarov N.K., Tillaev M.T. Patent of the Republic of Uzbekistan No. 4372. "Auxiliary vas deferens to gin saws." Tashkent-1997

2. Safarov N.K. "A working chamber with an additional ejaculatory device" (Patent RUz No 1112). 